\title{
Magnitude of sedentary behavior and associated factors among secondary school adolescents in Debre Berhan town, Ethiopia
}

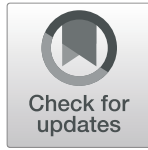

\author{
Osman Yimer Mohammed ${ }^{1 *}$ (D), Esubalew Tesfahun² and Abdurahman Mohammed $^{3}$
}

\begin{abstract}
Background: Sedentary life style is becoming increasingly common in this industrial age due to changes on the way people manufacture, transport and communicate. Sedentary lifestyle is associated with chronic diseases (diabetes, cardiovascular disease, and cancer), depression, obesity and premature mortality. The objective of this study was to assess the magnitude and associated factors of sedentary behavior.

Methods: School based cross sectional study was conducted among 580 students from April 20 to May 10, 2019 in secondary schools in Debre Berhan City Administration. Sedentary behavior was measured using time spent on four activities (watching TVNideo, listening to music, surfing internet and playing games). Adolescents are considered sedentary if they spend two or more hours in one or all listed activities per day. Data was entered to Epidata version 4.2.2.1 and exported to SPSS version 20 for analysis.

Result: A total of 580 (44.3\% male and 55.7\% female) students participated in this study. The magnitude of sedentary behavior ( $\geq 2 \mathrm{~h}$ per day) was $65.5 \%(95 \% \mathrm{Cl}=61.32 \%$ - 69.08). Family monthly income greater than 8000 birr (AOR: $6.42,95 \% \mathrm{Cl}=2.18-18.78$ ), maternal education (AOR: $5.12,95 \% \mathrm{Cl}=1.09-23.83$ ), access to TV (AOR: 4.87, $95 \% \mathrm{Cl}=1.99-11.87$ ), access to mobile internet (AOR: $2.37,95 \% \mathrm{Cl}=1.14-4.93$ ) and utilization of social media (AOR: $2.98,95 \% \mathrm{Cl}=1.43-6.17$ ) were positively associated with adolescent sedentary behavior.

Conclusion: The prevalence of sedentary behavior was high among adolescents of Debre Berhan town. Therefore, schools in the town should work towards creating awareness on the wise use of screen based entertainments.
\end{abstract}

Keywords: Sedentary behavior, Internet access, Social media, Maternal education

\section{Introduction}

Sedentary behavior is defined as any waking behavior characterized by an energy expenditure $\leq 1.5$ METs while in a sitting or reclining posture [1]. Sedentary behavior includes television (TV) viewing, video game playing, computer use, reading, talking on the telephone, and sitting while commuting by automobile, bus, train, plane and ferry which all require an energy expenditure between 1.0 and 1.5 metabolic equivalent (METs) [2]. Sedentary behavior is very much influenced by industrial revolution which changes the way people manufacture, transport and communicate [2]. $23 \%$ of adults aged 18 years and above and $81 \%$ of

\footnotetext{
*Correspondence: oyimer86@gmail.com

${ }^{1}$ College of health Sciences, Department of Midwifery, Debre Berhan

University, Debre Birhan, Ethiopia

Full list of author information is available at the end of the article
}

adolescents (84\% female and $78 \%$ male) are insufficiently physically active [3]. Screen time (ST) among high school students is higher compared with elementary [4]. Sedentary lifestyle is associated with ill health like chronic diseases (diabetes, cardiovascular disease, and cancer), higher depression and obesity [5-8]. Non-communicable diseases (NCDs) cause $70 \%$ of deaths globally, ranging from $37 \%$ in low-income countries to $88 \%$ in high-income countries [9].

Non-communicable diseases which includes heart diseases, various forms of cancer and diabetes mellitus claimed the life of 2.7 million people $(28.6 \%$ of all deaths) in 2012 and 3.1 million people $(33.5 \%$ of all deaths) in 2015 [10, 11]. In Ethiopia, non-communicable diseases such as cardiovascular diseases, diabetes mellitus and cancer caused 34\% of all deaths in 2008 and $40 \%$ of all deaths in 2014 [12, 13]. 
Age, sex, socioeconomic status (higher family income), education (grade level), higher level of maternal education, parents' occupation, media accessibility, experimentation with alcohol, being overweight are associated factors for sedentary behavior $[4,8,14-20]$. The magnitude of sedentary behavior and its correlates are well studied among developed and middle income countries. However, such studies are very rare in Sub-Saharan region. Similarly, the status of sedentary behavior and its associated factors are not well studied in Ethiopia. Furthermore, the gross school attendance ratio in Ethiopia is 91\%. School attendance rate is high among adolescents in the urban area and the physical inactivity level is also high globally among these age group [3, 21]. Therefore, the objective of this study was to assess magnitude of sedentary behavior and its associated factors among adolescents of secondary schools in Debre Berhan City Administration, 2019.

\section{Methods and materials}

\section{Study design and setting}

A school based cross sectional study was conducted among secondary school adolescents in Debre Berhan City Administration from April 20 to May 10, 2019. Debre Berhan City Administration is the capital of North Shoa administrative zone of Amhara Regional state. It is located $695 \mathrm{~km}$ from Bahir Dar, the capital of Amhara Regional State, and $130 \mathrm{kms}$ from Addis Ababa, the capital of Ethiopia. The town has four governmental and one private secondary Schools. In 2018/19 academic year, there were 11,111 secondary school students in the town.

\section{Sampling procedures}

Multistage stratified simple random sampling technique was used to select the study participants. Primarily, the schools were stratified into two strata, public and private schools. Then, two public and one private schools were first selected by simple random sampling. After that, the sample size was allocated to each high school proportional to the number of students in each schools. Similarly, the allocated number was also distributed to each grade level (grade 9, 10, 11 and 12) proportionally. Finally, students were selected using computer generated simple random sampling from each section.

\section{Operational definition}

Screen based sedentary time: Time spend watching $\mathrm{TV}$, Listening music, using Internet, playing mobile and computer game.

Positive for Sedentary Behavior: Adolescents who have $\geq 2 \mathrm{~h}$ average screen based sedentary time per day [2].

Adolescent: in this research are students between the age of 13 and 19.

\section{Data collection tool and procedures}

A pretested, Interviewer Guided self-administered, structured questionnaire was used. Sedentary behavior was assessed using questions generated from the sedentary behavior questionnaire (SBQ), HELENA study sedentary questionnaire and different related researches [4, 22, 23]. Sedentary behavior was assed using four items which includes watching TV/Video, listening music, playing computer or mobile game and using internet. The internal validity of the items were assessed using Cronbach alpha test during the pretest ( $\alpha$-coefficients 0.76$)$. Sociodemographic variables like sex, age, grade level, residence, housing type, parent education, household monthly income, parent occupation, access to TV, access to mobile-phone, access to internet, access to play ground and gymnasium were assessed. The English version of the structured questionnaire was translated into the local language, Amharic and back translated to English.

\section{Data processing and analysis}

The collected data were checked manually at the site of data collection for completeness and consistency. The cleaned data were entered to Epidata version 4.4.2.1 software and exported to Statistical Package for Social Sciences (SPSS) version 20 software for analysis. Descriptive statistic was used to summarize the socio-demographic characteristics and sedentary behavior.

Sedentary status was determined by categorizing the average time spent on the four sedentary activities into < $2 \mathrm{~h}$ and $\geq 2 \mathrm{~h}[24,25]$. To identify associated factors to sedentary behavior, bivariate logistic regression was performed to each independent variable with the dependent variable. Those variables with $p$ value $<0.2$ in the bivariate logistic regression analysis were included in the multiple logistic regression. Strength of association was measured using odds ratio, and 95\% confidence interval. Statistical significance was declared at $\mathrm{p}$ value $<0.05$.

Screen based sedentary time was calculated by adding media related times (watching TV/Video, listening music, using internet and playing mobile and computer games); multiplying week day sum by five and weekend day by two and divide the sum of the two by seven. Adolescents with mean hours 2 and above were classified as sedentary.

\section{Results}

\section{Socio-demographic characteristics}

A total of 580 adolescents were participated in this study, which yields a response rate of $98.14 \%$. The reason for nonparticipants were absenteeism at the time of data collection and reluctance to respond during repeated attempts made to communicate after the data collection time. Among the study participants, 257 (44.3\%) were male and 323 (55.7\%) were female with median age of 18 years (IQR: 16-18). 
About 215 (37.1\%) were from grade 10 and 549 (94.4\%) were Orthodox Christian (Table 1).

\section{Adolescent's family socio-demographic characteristics} From the total families of the study participants 362 (62.4\%) were from Urban provinces and 407 (70.2\%) live in their own house, 184 (31.7\%) mothers and 144 (24.8\%) father of adolescents were not attended formal education. About 341 (75.9\%) mothers were house wives and 216 (37.2\%) fathers were farmers. Concerning family income, the median income was 5000 with the interquartile range (IQR) 2000-8000 (Table 1).

\section{Adolescents media access and characteristics of the living environmental}

Among all adolescents who participated in this study 417 (71.9\%) had access for television, 435 (59.5\%) had access to satellite dish, 339 (58.4\%) had playground around their residence and 106 (27.6\%) had access for gymnasium. About 432 (74.5\%) adolescents had access to mobile phone and $67.82 \%$ (293/ 432) of them had access for mobile internet connection. A total 253 (43.6\%) used social media (Table 1).

\section{Sedentary time and behaviors}

Among the total participants 387(65.2\%) [28.38\% male and $36.9 \%$ female] were found to be sedentary $(95 \% \mathrm{CI}=$ $61.32 \%$ - 69.08). The average screen based sedentary time was $3.3 \mathrm{~h}(3.3 \pm 2.29 \mathrm{SD})$. Watching TV/Video (1.22) contributed more time for sedentary behavior. All sedentary times spend doing different activities showed a slight increment at the weekend compared with the week days (Table 2).

\section{Factors associated with sedentary behavior of} adolescents among high school students in Debre Berhan town

Binary logistic regression was conducted between status of sedentary behavior and all dependent variables. Dependent variables with $P$-Value less than 0.2 like, grade, Family monthly income, mothers' education, fathers' education, mother' occupation, father' occupation, family residence, house status, access to TV, access to satellite dish, access to mobile internet and social media utilization were included to multiple regression analysis.

The result of multiple logistic regression model revealed that monthly income, maternal education, access to television, mobile internet and social media utilization found to be statistically significant. Accordingly, adolescents whose family earn more than 8000 per month were 6.42 (AOR $6.42,95 \% \mathrm{CI}=2.18-18.78$ ) times more likely to be sedentary compared with those whose families earn less than 2000 birr.
Adolescents who have educated mother were 5.12 (AOR 5.12, 95\%CI $=1.09-23.83$ ) times more likely to be sedentary compared with those who have uneducated mother. Adolescents who have access to TV were 4.87 (AOR 4.87, 95\% CI $=1.99-11.87$ ) time more likely to be sedentary than those who do not have access to TV. Adolescents who used social media were also 2.98 (AOR 2.98, 95\%C I = 1.43-6.17) times more likely to be sedentary than those who did not use social media (Table 3).

\section{Discussion}

This study tried to measure the magnitude of sedentary behavior and associated factors. The prevalence of sedentary behavior was high (65.2\%). A Number of factors were identified to be positively associated with sedentary behavior and they are consistent with past researches. These includes family monthly income, maternal education, access to media, access to mobile internet and social media utilization.

The prevalence of screen based sedentary behavior $(\geq 2 \mathrm{~h}$ ) was $65.5 \%$. This was similar with study conducted in Brazil and Scotland which reported that the prevalence was around 69.2 and $68.6 \%$ respectively $[14,26]$. The similarity may be due to the entertaining nature of media affects adolescents in the same way. This study finding was not consistent with other study in Canada, which reported the prevalence of sedentary behaviors to be $25.4 \%$ [27]. The inconsistency might be due to the difference on the measurement of sedentary behavior and the cut of point considered.

High socioeconomic status and high maternal education were associated with high screen time $(>2 \mathrm{~h})$. This was consistent with studies conducted in Brazil. Accordingly, higher maternal education and higher family income were positively associated with more screen time [14, 18]. Another study in Ghana also reported that affluence was the main contributing factor for higher sedentary behavior [8]. This may be due to educated mother seeks information making them close to media so as their children and wealth makes media facilities accessible to the family $[21,28]$.

Access to media like TV was associated with high sedentary time. It was consistent with study in china which reported that media access was positively correlated with high screen time [4]. The similarity might reflect the similar effect of exposure to TV. Access to internet and use of social media were another significant predictor of sedentary behavior in our study. Age, grade level, occupation, residence, house status and access to satellite dish were not significantly associated factors. 
Table 1 Sociodemographic, Family Characteristics and Access to Media and Environmental Facility of Adolescents among high school students in Debre Berhan Town, Ethiopia, 2019

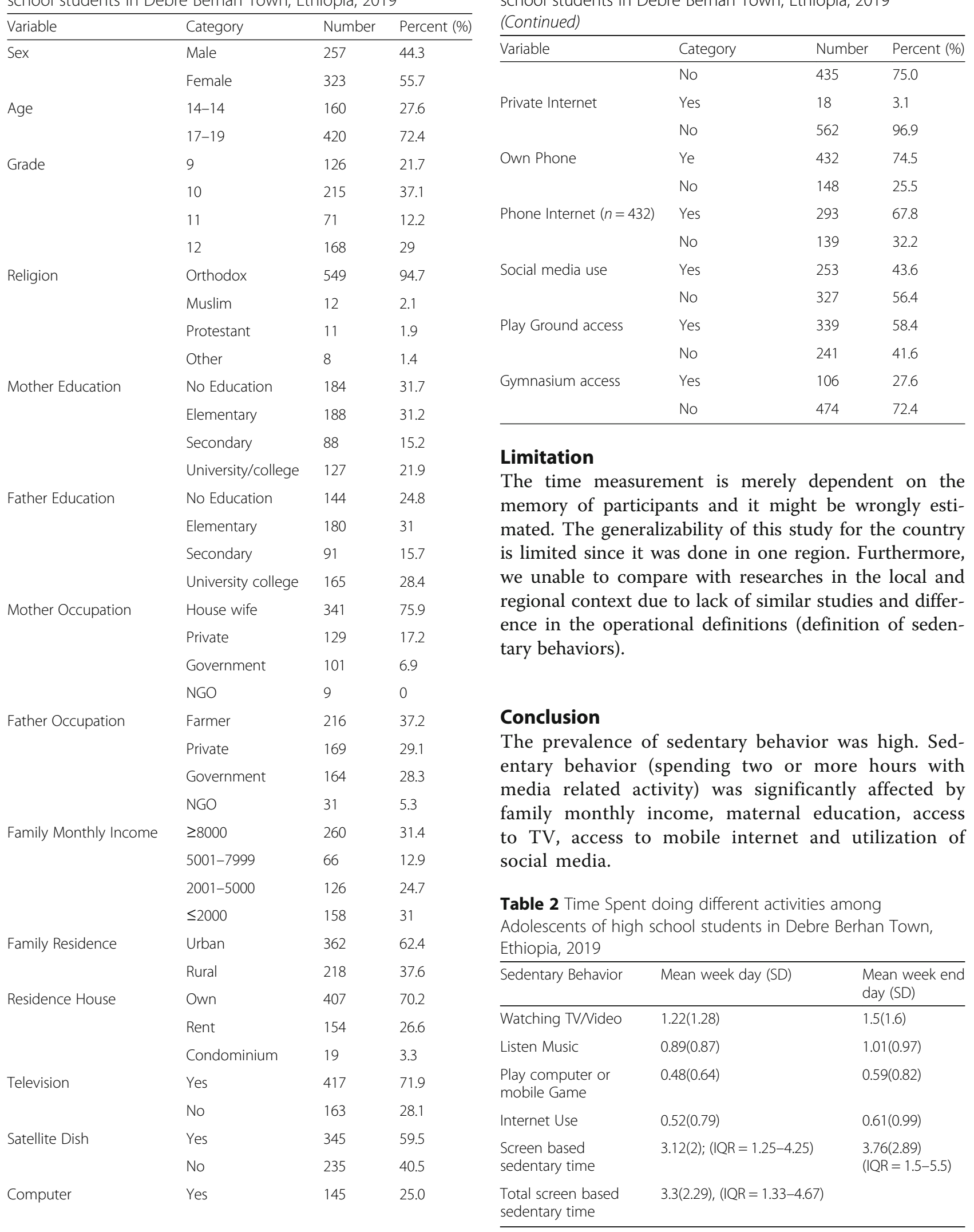

Table 1 Sociodemographic, Family Characteristics and Access to Media and Environmental Facility of Adolescents among high school students in Debre Berhan Town, Ethiopia, 2019 (Continued) mated. The generalizability of this study for the country we unable to compare with researches in the local and regional context due to lack of similar studies and difference in the operational definitions (definition of seden- 
Table 3 Factors associated with Sedentary Behavior of adolescents among High school students in Debre Birhan, Ethiopia, 2019

\begin{tabular}{|c|c|c|c|c|c|}
\hline Variables & & Sedentary & Not Sedentary & COR & $\mathrm{AOR}(95 \%-\mathrm{Cl})$ \\
\hline \multirow[t]{4}{*}{ Grade level } & $G=9$ & 73 & 53 & 1 & 1 \\
\hline & $G=10$ & 124 & 91 & 1.95 & $0.39(0.13-1.23)$ \\
\hline & $\mathrm{G}=11$ & 59 & 12 & 0.54 & $1.22(0.58-2.53)$ \\
\hline & $\mathrm{G}=12$ & 122 & 46 & 1.93 & $0.82(0.35-1.90)$ \\
\hline \multirow[t]{4}{*}{ Family Monthly Income } & $<2000$ & 66 & 92 & 1 & 1 \\
\hline & $2001-5000$ & 72 & 54 & 5.92 & $1.81(0.64-5.17)$ \\
\hline & 5001-7999 & 44 & 22 & 3.94 & $1.45(0.52-4.04)$ \\
\hline & $>8000$ & 142 & 18 & 10.99 & $6.42(2.18-18.78)^{* * * *}$ \\
\hline \multirow[t]{4}{*}{ Maternal Education } & No Education & 79 & 105 & 1 & 1 \\
\hline & Elementary & 114 & 67 & 0.96 & $2.16(0.51-9.17)$ \\
\hline & Secondary & 76 & 12 & 3.56 & $5.12(1.09-23.83)^{*}$ \\
\hline & College University & 109 & 18 & 8.05 & $4.40(0.842-22.99)$ \\
\hline \multirow[t]{4}{*}{ Father Education } & No Education & 51 & 93 & 1 & 1 \\
\hline & Elementary & 108 & 72 & 1.12 & $0.85(0.23-3.10)$ \\
\hline & Secondary & 77 & 14 & 4.12 & $0.61(0.14-2.69)$ \\
\hline & College University & 142 & 23 & 11.25 & $0.95(0.19-4.85)$ \\
\hline \multirow[t]{4}{*}{ Mother Occupation } & NGO & 7 & 2 & 3.243 & $0.88(0.10-7.39)$ \\
\hline & Government & 84 & 17 & 0.605 & $0.81(0.09-7.04)$ \\
\hline & Private & 110 & 19 & 0.708 & $0.39(0.04-3.64)$ \\
\hline & House wife & 177 & 164 & 1 & 1 \\
\hline \multirow[t]{4}{*}{ Father Occupation } & NGO & 26 & 5 & 9.02 & $4.58(0.58-35.92)$ \\
\hline & Government & 135 & 29 & 1.17 & $0.88(0.13-5.80)$ \\
\hline & Private & 138 & 31 & 1.12 & $1.78(0.27-11.75)$ \\
\hline & Farmer & 79 & 137 & 1 & 1 \\
\hline \multirow[t]{2}{*}{ Family Residence } & Urban & 295 & 67 & 7.16 & $0.370 .13-1.06)$ \\
\hline & Rural & 83 & 135 & 1 & 1 \\
\hline \multirow[t]{3}{*}{ Housing condition } & Own & 293 & 114 & 2.71 & $0.75(0.37-1.53)$ \\
\hline & Rent & 75 & 79 & 2.31 & $1.02(0.18-5.69)$ \\
\hline & Condominium & 10 & 9 & 1 & 1 \\
\hline \multirow[t]{2}{*}{ TV } & Yes & 330 & 87 & 9.09 & $4.87(1.99-11.87)^{* * *}$ \\
\hline & No & 48 & 115 & 1 & 1 \\
\hline \multirow[t]{2}{*}{ Dish } & Yes & 289 & 59 & 7.54 & $1.132(0.456-2.82)$ \\
\hline & No & 92 & 143 & 1 & 1 \\
\hline \multirow[t]{2}{*}{ Computer } & Yes & 127 & 18 & 5.17 & $1.26(0.46-3.44)$ \\
\hline & No & 251 & 184 & 1 & 1 \\
\hline \multirow[t]{2}{*}{ Private Internet } & Yes & 16 & 2 & 4.42 & $0.62(0.09-4.07)$ \\
\hline & no & 362 & 200 & 1 & 1 \\
\hline \multirow[t]{2}{*}{ Phone } & Yes & 301 & 131 & 2.12 & $1.33(0.85-2.33)$ \\
\hline & No & 77 & 71 & 1 & \\
\hline \multirow[t]{2}{*}{ Mobile Internet } & Yes & 236 & 57 & 2.37 & $2.37(1.14-4.93)^{*}$ \\
\hline & No & 65 & 74 & 1 & 1 \\
\hline \multirow[t]{2}{*}{ Social media } & Yes & 213 & 40 & 5.23 & $2.98(1.43-6.17)^{* *}$ \\
\hline & No & 165 & 162 & 1 & 1 \\
\hline
\end{tabular}




\section{Recommendation}

\section{To North Shoa and Debre Berhan City education office}

- Better to avail facilities and mainstream the education on life style with the main academic program to enhance behavioral change

\section{To secondary schools}

- Better to create awareness regarding the recommended time to spend on screen based entertainment.

\section{Abbreviations}

AOR: Adjusted Odds Ratio; Cl: Confidence interval; COR: Crude Odds Ratio; IQR: Interquartile range; METs: Metabolic Equivalent; NCD: None communicable disease; SBQ: Sedentary behavior Questionnaire; SD: Standard Deviation; TV: Television

\section{Acknowledgments}

We would like to gratefully acknowledge Debre Berhan University, the high school principals, teachers and students for their support and participation in our study.

\section{Authors' contributions}

The first author [OY] is the principal investigator and involved in the designing, data collection, analysis and preparing the manuscript. The second author [ET] involved in the design, analysis and manuscript preparation. The third author [AM] involved in the analysis and writing the manuscript. All the authors had read and approved the final manuscript.

\section{Funding}

Not Applicable.

\section{Availability of data and materials}

The data set used in this study is available from corresponding author on reasonable request.

\section{Ethics approval and consent to participate}

This research was approved by the review committee of Debre Berhan University, College of Health Sciences. Permission to conduct the study was obtained from each school administrators. Consent and assent and written consent from the parents (for participants younger than 18 years old) was obtained from the study participants and anonymity and confidentiality of the data were maintained throughout the data collection process. All participants were informed that they have the right to refuse participating in the study at any time.

\section{Consent for publication \\ Not Applicable.}

\section{Competing interests}

The authors declared that they have no competing interests.

\section{Author details}

${ }^{1}$ College of health Sciences, Department of Midwifery, Debre Berhan University, Debre Birhan, Ethiopia. ${ }^{2}$ College of health Sciences, Department of Public Health, Debre Berhan University, Debre Birhan, Ethiopia. ${ }^{3}$ College of health Sciences, Department of Nursing, Debre Berhan University, Debre Birhan, Ethiopia.

Received: 29 August 2019 Accepted: 9 January 2020

Published online: 20 January 2020

\section{References}

1. Mark T. "Standardized use of the terms "sedentary" and "sedentary behaviours"." Appl Physiol Nutr Metab. 2012;37:540-2.
2. Carmen J, Daniela S, Michael FL. Introduction to sedentary behaviour epidemiology. In: Sedentatry behaviour epidemiology. Switzerland: Springer International Publishing AG; 2018. p. 3-29.

3. World Health Organization. Global status report on noncommunicable diseases 2014. World Health Organization; 2014.

4. Miles L. Physical activity and health: British Nutrition Foundation; 2007. p. 314-63.

5. VicHealth. Reducing prolonged sitting in the workplace. (An evidence review: summary report). Melbourne: Victorian Health Promotion Foundation; 2012

6. Kirsi HP, Jaakko K, Patrik B, Guy P, Hannele Y, Urho MK, Richard JR, Klaas RW, Aila R. Physical inactivity and obesity: A vicious circle. Obesity (silver spring). 2008;16(2):409-14.

7. Mavis A, Samuel A. The relationship between physical activity, sedentary behaviour and mental health in Ghanaian adolescents. Child Adolesc Psychiatr1y Ment Health. 2015;9(11)

8. WHO. Fact Sheet, The top 10 causes of death. 2017.

9. Africa Check. Africa Check. 2017. Available from: https:/africacheck.org/factsheets/ factsheet-the-leading-causes-of-death-in-africa/. [cited 2017 October 16]

10. Vuuren PJV. 2017 [cited 2017 October 16. Available from: https://africacheck. org/factsheets/factsheet-africas-leading-causes-death/.

11. WHO. WHO Coutry Cooperation strategy 2012-2015, Ethiopia. Republic of Congo: WHO Regional Office for Africa; 2013. Report No.: 9789290232070

12. Awoke M, Damen HM, Tekebash A. The Double Mortality Burden Among Adults in Addis Ababa, Ethiopia, 2006-2009. CDC, Prev Chronic Dis. 2012; 9(11_0142).

13. Ferreira RW, Rombaldi AJ, Ricardo LI, Hallal PC, Azevedo MR. Prevalence of sedentary behavior and its correlates among primary and secondary school students. Revista Paulista de Pediatria. 2016;34(1):56-63.

14. Dias PJ, Domingos IP, Ferreira MG, Muraro AP, Sichieri R, Gonçalves-Silva RM Prevalence and factors associated with sedentary behavior in adolescents. Revista de saude publica. 2014;48(2):266-74.

15. Anderson S, Currie CL, Copeland JL. Sedentary behavior among adults: the role of community belonging. Prev Med Rep. 2016:4:238-41.

16. Deliens T, Deforche B, De Bourdeaudhuij I, Clarys P. Determinants of physical activity and sedentary behaviour in university students: a qualitative study using focus group discussions. BMC Public Health. 2015;15(1).

17. Mielke Gl, Brown WJ, Ekelund U, Brage S, Gonçalves H, Wehrmeister FC, Menezes AM, Hallal PC. Socioeconomic position and sedentary behavior in Brazilian adolescents: a life-course approach. Prev Med. 2015;107:29-35.

18. Ye S, Chen L, Wang Q, Li Q. Correlates of screen time among 8-19-year-old students in China. BMC Public Health. 2018;18(1).

19. Rey-López JP, Tomas C, Vicente-Rodriguez G, Gracia-Marco L, Jiménez-Pavón D, Pérez-Llamas F, Redondo C, Bourdeaudhuij ID, Sjöström M, Marcos A, Chillón P. Sedentary behaviours and socio-economic status in Spanish adolescents: the AVENA study. Eur J Pub Health. 2010;21(2):151-7.

20. You C, Zhonghui Z, Jinyao YJinyao Y, Shuqiao Y. Associations between physical inactivity and sedentary behaviors among adolescents in 10 cities in China. BMC Public Health. 2014;14(744)

21. EDHS. Ethiopia demographic and health survey 2016. Addis Ababa: Central statistical agency; 2016. 21. The DHS program ICF Rockville, Maryland, USA. July 2017. 14-22

22. Rosenberg DE, Norman GJ, Wagner N, Patrick K, Calfas KJ, Sallis JF. Reliability and validity of the sedentary behavior questionnaire (SBQ) for adults. J Phys Act Health. 2010;7(6):697-705.

23. Rey-López JP, Ruiz JR, Ortega FB, Verloigne M, Vicente-Rodriguez G, GraciaMarco L, Gottrand F, Molnar D, Widhalm K, Zaccaria M, Cuenca-García M. Reliability and validity of a screen time-based sedentary behaviour questionnaire for adolescents: The HELENA study. European J Public Health. 2011;22(3):373-7.

24. Expert Panel on Integrated Guidelines for Cardiovascular Health and Risk Reduction in. Expert panel on integrated guidelines for cardiovascular health and risk reduction in children and adolescents. summary report. Pediatrics; 2011

25. Australian Government - Department of Health. Make your move - sit less. Become active for life! Australia's physical activity and sedentary behavior guidelines: adults. 201

26. Gorely T, Atkin AJ, Biddle SJ, Marshall SJ. Family circumstance, sedentary behaviour and physical activity in adolescents living in England: Project STIL. Int. J. Behav. Nutr. Phys. Act. 2009;6(1). 
27. Poobalan AS, Aucott LS, Clarke A, Smith WC, et al. BMC public health. 2012;12(1).

28. Sherar LB, Griffin TP, Ekelund U, Cooper AR, Esliger DW, van Sluijs EM, Andersen LB, Cardon G, Davey R, Froberg K, Hallal PC. Association

between maternal education and objectively measured physical activity and sedentary time in adolescents. J Epidemiol Community Health. 2016;70(6):541-8.

\section{Publisher's Note}

Springer Nature remains neutral with regard to jurisdictional claims in published maps and institutional affiliations.

Ready to submit your research? Choose BMC and benefit from:

- fast, convenient online submission

- thorough peer review by experienced researchers in your field

- rapid publication on acceptance

- support for research data, including large and complex data types

- gold Open Access which fosters wider collaboration and increased citations

- maximum visibility for your research: over $100 \mathrm{M}$ website views per year

At BMC, research is always in progress.

Learn more biomedcentral.com/submissions 